\title{
Retro-diagnosis methodology for land consumption analysis towards sustainable future scenarios: Application to a mediterranean coastal area
}

\author{
Salvador García-Ayllón \\ Technical University of Cartagena, UPCT. Department of Civil Engineering, Paseo Alfonso XIII, 50, 30203, Cartagena, Spain
}

\section{A R T I C L E I N F O}

\section{Article history:}

Received 12 July 2016

Received in revised form

14 February 2018

Accepted 15 February 2018

Available online $\mathrm{xxx}$

\section{Keywords:}

Regional sustainability

Smart coastal territory

GIS-LiDAR retrospective analysis

Land consumption

Campo de cartagena-Mar Menor area

\begin{abstract}
A B S T R A C T
Land consumption is a good indicator to directly diagnose present and future imbalances in territories, and indirectly, possible issues associated to the management of other resources. Therefore, after reaching the target of standardizing urban research that makes it possible to build healthier and greener cities, the real challenge for the future is to make the leap from urban scale to regional scale and deploy these policies in an integrated manner, in so-called "smart territories".

In that context, this paper presents a model of multidisciplinary analysis through indicators based in land consumption and transformation rates. The model, called GIS-LiDAR retrospective analysis, is implemented through territorial information tools in order to simulate and diagnose possible future imbalances based on past and current trends. This innovative methodology will be applied in a Spanish Mediterranean coastal area called the Campo de Cartagena, a territory with issues related to low-density urban sprawl, intensive agriculture and mass tourism coastal urbanization. This territory of high economic activity and with important environmental protected areas like the Mar Menor lagoon as well as complex interrelated phenomena will be "retrohistorically" diagnosed from the perspective of land transformation over 60 years. The method, designed to advance future scenarios and help planners in decision-making, will show dangerous current trends leading to imbalances in this area so that future planning can be implemented with smart (sustainable) criteria.
\end{abstract}

(c) 2018 Elsevier Ltd. All rights reserved.

\section{Introduction}

A frequent controversial issue in developed countries refers to the influence of human activities on territory and its consumption of resources (Allais et al., 2015). Maintaining a careful balance between actions required for economic development, such as construction, agriculture or tourism, and the adequate conservation of the natural assets of territory is at times a complex equation difficult to solve (McCormick et al., 2013). The governance of the territory and the correct management of economic activities in relation to land consumption and its impact is one of the challenges of the future in modern societies, where economic activity must coexist inexorably with the environment (Zhang et al., 2015). In this context, one important field in the study of the impact of human activities is the determination of the behaviour pattern and the areas of influence of such activities to implement sustainable

E-mail address: salvador.ayllon@upct.es. management of existing resources (Ben Letaifa, 2016).

The many variables that shape the development of territory require analysis in very different fields (economic, political, social, etc.). Decisions such as the pattern of urban growth, building infrastructure or landscape transformation for boosting economic activities are all issues to be addressed by assessing resource consumption with sustainability criteria (Callaway, 2016). Therefore, a large number of interrelated parameters that influence an iterative process which usually feeds on itself must be taken into account (Hashem et al., 2016).

In the last two decades, numerous initiatives encompassed under the concept of "smart city" have been developed aimed at providing a more sustainable framework for the improvement of metropolitan areas. However, this concept, implemented through innovation, the use of information technologies or optimization in the management of resources for example has widely diversified its meaning and scope in recent years (De Jong et al., 2015). During this time, the rather "classic" concept of smart city (Hollands, 2008; Nam and Pardo, 2011) has been evolving, being the subject of 
reflection and analysis by various authors (Deakin and Al Wear, 2011; Lee et al., 2013 or Zygiaris, 2013). The smart city was focused initially toward an integrated vision of multiple solutions to manage a city's assets (Mahizhnan, 1999; Odendaal, 2003), although the breadth of technologies that have been implemented under the smart city label have made it currently more difficult to pin down a concrete definition of the actual concept. Nowadays, usual approaches to a smart city concept address various topics such as energy efficiency, information technology, transport infrastructure, resource consumption, environmental impacts or even hazards, among others (Neirotti, 2014; Fraker, 2013). However, as many authors have recently postulated, the smart city concept (of strong and innovative theoretical charge) has been materialized in practice very often over the last years through isolated ideas or disjointed projects (Anthopoulos, 2017). On occasions it has even become simple political slogans or commercial marketing products with no chance of implementation, or without constituting a response to an actual need for real improvement in the city (Grossi and Pianezzi, 2017).

An aspect which policy-makers should pay attention to is the implementation of integrated territorial actions in these processes of transforming urban areas into real smart cities (Thite, 2011). Cases that are limited in range are readily available in the literature (Carter, 2013; Wey and Hsu, 2014). In this context, it is essential to perform a realistic proposal to introduce constraints and boundary conditions imposed by the territorial or sectoral regulations (O'Connell, 2009). In the field of enabling proposals to promote sustainable development, a common problem is very often the need to establish a spatial framework to address a coherent scope for action (a building, a neighbourhood, a specific parameter for the whole city, etc.). It is not difficult to find different successful examples in the specific literature, both pilot projects as well as material achievements (Walravens, 2015; De Jong et al., 2016). However, as some recent authors suggest, the current concept of smart city needs to evolve in a context where sustainability is an increasingly complex and evolving concept (Kummitha and Crutzen, 2017), if we seek to avoid many interesting proposals becoming isolated actions that cannot be incardinated in a suitable spatial framework to reach the target pursued. Current issues related to the sustainable management of resource consumption, transport or urban governance for example are not truly helpful if they approach only the geographical scope of a building or a neighbourhood (La Greca et al., 2011). The results obtained by this approach may lead to merely isolated actions with no connection to the rest of the city or the territory really affected by the issue analysed.

In this line, an aim to achieve in the transformation of these isolated actions into a true comprehensive performance (that would enable more sustainable and healthier areas) involves extending the classical concept of "smart cities" towards a wider idea of "smart territories". In developing this idea, the need to implement multidisciplinary assessment must be taken into account to provide government expertise in global planning (urban sprawl, industry development, infrastructure investments, etc.) with sustainable criteria (Amato et al., 2015). This work should be carried out through instruments that could diagnose and monitor management issues to facilitate decision-making for territorial governance beyond the simple geographical context of a classical administrative urban delimitation (Hader and Rodzi, 2009). This is a qualitative target that would allow societies to enhance the concept of Smart City, improving it into a more comprehensive framework such as Smart Territory. The framework of Smart Territory could actually be in some cases more consistent with the original purpose of sustainability and efficiency from the concept of smart city.

In this context, the use of GIS (Geographic Information Systems designed to capture, store, manipulate, analyse, manage, and represent spatial data) and LiDAR (surveying methods based on 3D technology to represent high precision cartography by laser) tools can be very helpful. These instruments are able to simulate future scenarios, thus allowing decision makers to restrain trends oriented towards unsustainability in the context of territory and resources management (Pozoukidou and Ntriankos, 2017). With that intention, this article presents an innovative method of multidisciplinary analysis based on indicators obtained through territorial information systems. The method, called GIS-LiDAR retrospective analysis, is designed to help decision-makers and authorities in territorial management. This way it will allow cities' land use policies to be optimized, generating synergies in planning and development with sustainable criteria for land consumption and other resources use. The methodology presents multiple applications since it allows to study how phenomena belonging to different disciplines (tourism, urban planning, environmental impacts or hazard risks, for example) can feed each other, giving rise to more complex problems. A situation of these characteristics (which requires methodologies such as these to be properly analysed), is presented for a Mediterranean coastal area, whose case will be diagnosed and evaluated through the simulation of future scenarios.

\section{GIS-LiDAR analysis methodology}

Land consumption is a very interesting indicator for the purposes of establishing growth and evolution patterns of a territory. Furthermore, it allows to homogenously evaluate growth forecasts of factors such as population, resource consumption, the need for infrastructure development or landscape transformation (Steinitz, 2000). Through inertial interpolation matrices of process behaviour, forward-looking statements of these factors can be set based on the trends observed in the different land types and the existing urban planning in a territory. To achieve this goal, a methodology based on four stages that will use various GIS and LiDAR tools (SDIMED, CartoMur, SitMurcia and IDERM) is proposed. However, the methodology is not restricted to these specific instruments, therefore researchers need not use these particular tools but can choose their own tools based on the best adaptation to the analysed territory.

To start with, the diagnosis towards the future must be made taking into account the various interconnected issues that make up the current scenario (driving forces, pressures of activities, impact on human well-being, impact on ecosystemic services and state-changes of the social ecosystem). Therefore, this work requires a prior analysis adapted to the specific case of study in order to select the appropriate variables (see Fig. 1 as a standard example).

This process is the first step of an integrated analysis set out in four phases. After selecting all analysis factors, they must be implemented in a GIS tool to permit their numerical evaluation. The tool should enable them to be studied in the context of a "retrohistorical" analysis. This analysis introduces the trends of land transformation in a limited time frame from a starting date until today. The analysis must meet certain minimum 
requirements to be valid. First, it must address a homogeneous and statistically significant timeframe of the overall process under study. This period must cover a minimum of 40 years in any case to allow a reasonable future scenario to be hypothesized, as it is not able to represent future scenarios beyond $25 \%$ of the time trend used. This is in order to maintain the robustness of the data and to avoid raising overly theoretical hypotheses in the final trend analysis. Likewise, the trend period posed should be evaluated in at least three verification points (dates) to ensure that there are no distortions and that the analysed scenarios are sufficiently significant. These checkpoints must generate stages of a similar value to ensure the trend criteria (differences no greater than 15-20\% depending on available historical mapping are understood to be reasonable). Intermediate points can also be selected to verify the absence of abnormal behaviour or distortions in the data obtained.

Considering the numerical formulation of trend analysis data, criteria can be established based on the implementation of the GIS tools index. In this regard, various formulations are correct for the implementation of these measurements. The current study has used the formulations of Ji et al. (2006) for land consumption metrics. Land consumption indices (LCI, Eqs. (1) and (2)) for example relate built-up area change in housing and commercial construction (in this case it will be tourism construction; industry has a secondary role in the case study presented) as the major driving factors in urban land conversion. On the other hand, landscape transformation by agriculture and the construction of transport infrastructures are major driving forces in non-urban land conversion (LCI, Eqs. (3) and (4)). These construction-based metrics can be used to effectively compare land consumption across jurisdictions and to analyse the relative contribution of different activities in land use. To calculate these metrics, data must first be obtained on city housing units, tourism establishments, agricultural development and road construction for the studied territory in the time periods corresponding to or close to the satellite imagery dates. We then defined four indices: the ratios of the percentage change of built-up land coverage to the percentage change of the housing units (HU); tourism units (TU); agricultural

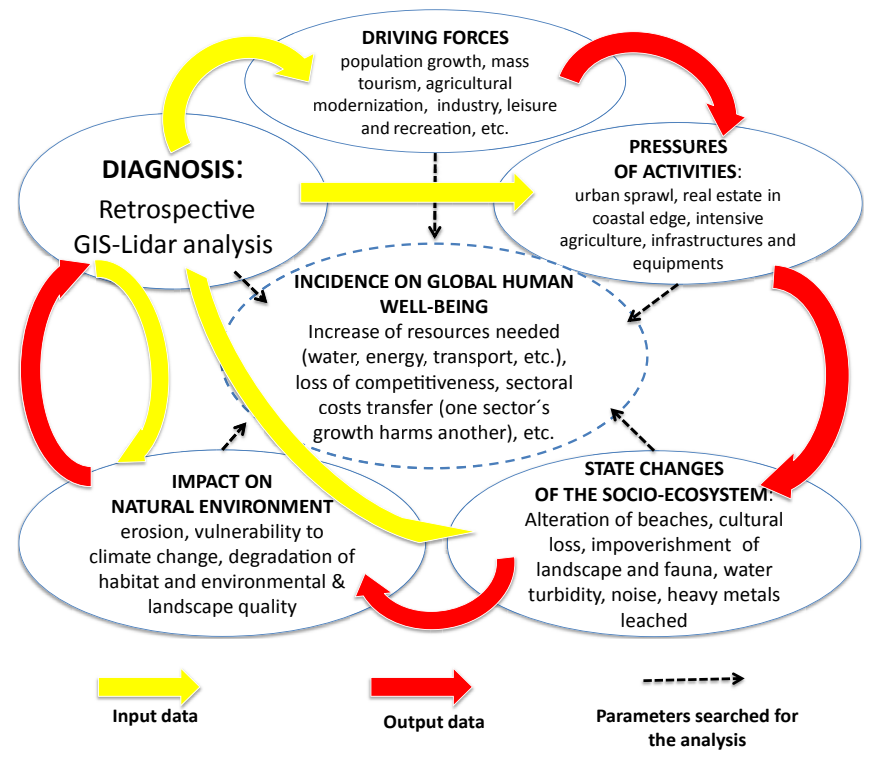

Fig. 1. Standard example of a flowchart for the development-impact process performed to select variables belonging to driving forces, pressures of activities, state changes of the socio-ecosystem and impacts on the natural environment. crops (AC); and road infrastructures (RI) in specific jurisdictions in a particular time period:

$L C I(H U)=\frac{\% \Delta D B_{\left(t_{1}-t_{0}\right)}}{\% \Delta[H U]_{\left(t_{1}-t_{0}\right)}}$

$L C I(T U)=\frac{\% \Delta D B_{\left(t_{1}-t_{0}\right)}}{\% \Delta[T U]_{\left(t_{1}-t_{0}\right)}}$

$L C I(A C)=\frac{\% \Delta D B_{\left(t_{1}-t_{0}\right)}}{\% \Delta[A C]_{\left(t_{1}-t_{0}\right)}}$

$L C I(R I)=\frac{\% \Delta D B_{\left(t_{1}-t_{0}\right)}}{\% \Delta[R I]_{\left(t_{1}-t_{0}\right)}}$

LCI land consumption index

HU housing unit (main housing) TU tourism unit (hotel beds, 2nd homes, resorts units)

AC agricultural crops RI road infrastructures

$\Delta$ DB percentage change in built-up land

$\Delta[\mathrm{HU}]$ percentage change in housing units $\Delta[\mathrm{TU}]$ percentage change in tourism units

$\Delta[\mathrm{AC}]$ percentage change in natural lands to agricultural crops $\Delta$ [RI] percentage change in road infrastructures

t0; t1 starting time; ending time

The third section of the method determines the current boundary conditions which the process performed is subject to. In this regard, it is important to incorporate constraints in the trend analysis from urban planning, infrastructure development, cultural heritage, landscape protection, agricultural characteristics, environmental planning, natural hazards, development of industrial activities, etc. in order to adapt future scenarios to current forecasts. This phase should be implemented using GIS-LiDAR tools to reach an accurate analysis and maintain numerical format homogeneity for comparison indices by transforming parameters (regardless of whether each subject maintains its own idiosyncrasy and specific procedure of analysis). The imposition of these boundary conditions can be made according to different criteria. In this case, values have been proposed based on those developed by different authors (Yue et al., 2013; Ren et al., 2012). In this context, the formulations employed to assess population density, urban sprawl or parcels are presented below (equations (5)-(7)):

$P D_{i}=\frac{\text { Pop }_{i}}{\text { Area }_{i}}$, Pop $=\sum_{i=1}^{n}$ Pop $_{i}$

where $i(i=1,2, \ldots, n)$ is the number of street-towns; Pop $_{i}$ is the population for street-town $\mathrm{i}$; and Area is the area of street-town $\mathrm{i}$.

$S I_{i}=\left[\frac{\left(S \%_{i}-D \%_{i}\right)}{100}+1\right] \times n$

where $\mathrm{SI}_{\mathrm{i}}$ is the sprawl index for area $\mathrm{i}$; $\mathrm{S} \%$ is the percentage of the total population in low-density edge growth or leapfrog growth parcels to the total population of an area and $\mathrm{D} \% \mathrm{i}$ is the percentage of the total population in high-density edge growth or leapfrog growth parcels to the total population of street-town $i$. 
ParcelPop $_{i j}=\frac{\text { Pop }_{i} \times k \times \text { SPArea }_{i j}}{\sum_{j=1}^{m} k \times \text { SPArea }_{i j}}$, Pop $=\sum_{j=1}^{m}$ ParcelPop $_{i j}$

where $i$ refers to the number of areas; $j(j=1,2, \ldots, m)$ refers to the $\mathrm{jth}$ residential or tourism land parcel of a territory; ParcelPop $\mathrm{p}_{\mathrm{ij}}$ is the estimated population of parcel $\mathrm{ij}$; $\mathrm{Pop}_{\mathrm{i}}$ is the population of area $\mathrm{i} ; \mathrm{k}$ is the modified coefficients, 1 for a low-rise habitation parcel and 14 for a multi-storey one (to simplify the analysis, residential land has been divided into two types: residential land Type I with multistorey buildings in the urban centres and some coastal areas, and residential Type II with low-rise buildings in tourist resorts and other coastal houses); SPArea $\mathrm{ij}_{\mathrm{ij}}$ is the area of residential or agricultural parcel ij. In the case of non-urban land, the criteria for identification and classification of agricultural land to determine the processes of transformation of natural soil to irrigated crops of intensive farming areas will be those of Corine Land Cover (Corine Land Cover, 2006).

The last phase of the process is really the future predictive diagnosis. This step should include at least land transformation forecasting, the determination of the most important resources needed in the scenario analysed (energy, water, etc.), the evaluation of the environmental risks and an urban development foresight in the context of sustainability. This latest analysis must take into account the possible behaviours of stakeholders. The results obtained may prove very interesting for policy makers who can implement (based on this new information) strategic actions. Such actions can later become operational programs to correct wrong trends raised by the retrospective GIS-LiDAR analysis performed.
The set of actions described for the whole process can be observed in Fig. 2.

\section{Application to a case study}

\subsection{Boundary conditions of the environment analysed}

Coastal regions are usually territories of high economic activity. In the case of Spain, 50\% of the GDP and of the population is located along the Mediterranean coastline (Marti et al., 2017). Apart from the needs of growing cities, tourism is the main factor of demand in this area. This market, strongly associated with second homes or resort developments for foreign tourists, generated a major housing bubble between 1995 and 2007, which, when it burst, led to a major economic crisis in the area (Nicodemo and Raya, 2012).

One of the most recognizable variables of urban development on the Mediterranean territories of Southeastern Spain in recent decades has been its high consumption of resources. Models of urban development based on low-density urban sprawl have proliferated in this area. The so-called tourist resorts are especially interesting in this field: important areas that urbanized coastal territories, but not too close to the coastline to avoid higher land prices.

In contrast to the high-density urban frontline beach models developed in Spain during the decades of the 1960s, 1970s and 1980s (Garcia-Ayllon, 2016), these new small low-density cities have generally been located near large communication infrastructures and are often accompanied by facilities such as a golf

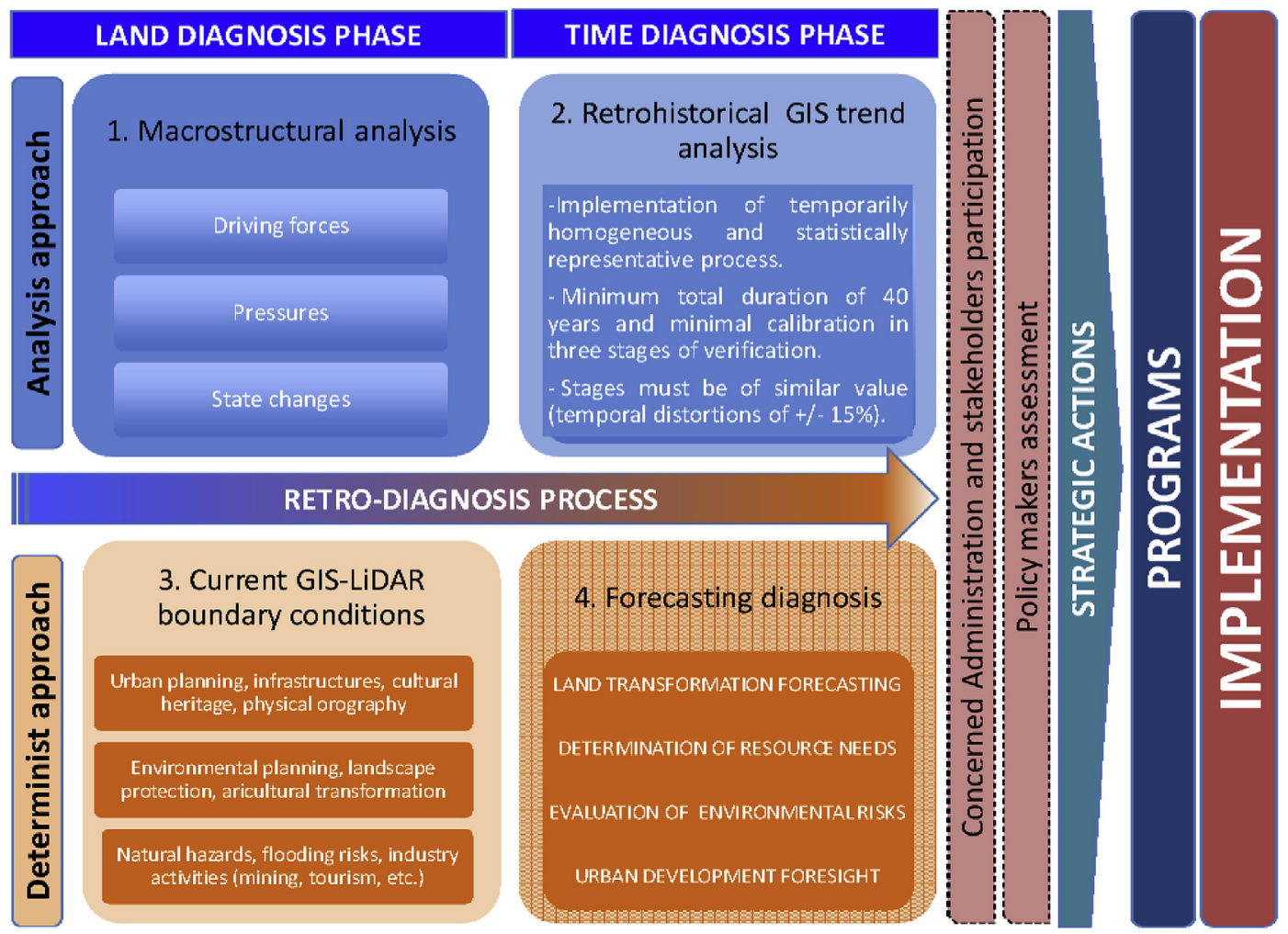

Fig. 2. Schematization of the GIS-LiDAR retrospective analysis model. 
course. Interesting analyses about their development patterns can be found in the specific literature (see for example the polyp model of Mena, 2010). In this sense, some of the main parameters highlighted by these types of urban growth are their low population density but also a controversial consumption of resources per capita (Palmer and Mathel, 2010); especially those related to the consumption of water, energy and transportation needs (Cole, 2009).

On the other hand, agriculture is another interesting economic activity linked to territorial development in these coastal regions. In this field, we can find the so-called "orchard of Europe", located in the south-east of Spain. This environment of high capacity generation of agrifood products for consumption in many countries of Europe requires various boundary conditions to become a competitive industry. Thus, one of the most essential aspects for that industry is the need for water, which has been enhanced in recent decades with the transfers between hydrographic river basins allowing new areas of intensive agriculture to proliferate (Martinez-Alvarez et al., 2017). This intensive agriculture sometimes involves a difficult cohabitation with protected natural areas. For example, contributions of nitrates carried by the wadis cross the crop fields where fertilizers are used to make it competitive (see the interesting case study of the Mar Menor protected area in PerezRuzafa et al., 2005 or Velasco et al., 2006).

Another aspect required for the commercialization of all this industry has been the development of infrastructures (highways, treatment plants, etc.), often financed in the context of European cohesion policies. This situation has also led to a significant landscape transformation, which in some regions such as Almeria
(Spain) has generated the so-called "plastic seas" territories. All these phenomena can be seen summarized in Fig. 3.

Apart from the issues identified, several others can commonly be found as a result of anthropic pressures from a variety of economic activities such as mining, industry, fishing, risks from floods erosion or construction work in rivers. These problems are often especially pronounced in the Mediterranean weather which corresponds to a semi-arid climate (less than $300 \mathrm{~mm} / \mathrm{year}$ ) where the rains are developed in a timely but torrential manner during the autumn months. For a comprehensive diagnosis of these complex phenomena in which the different variables are usually interrelated, the methodology presented is proposed.

\subsection{Analysis: application to the Mediterranean coastal area Mar Menor-Campo de Cartagena}

The Mar Menor-Campo de Cartagena area, located on the southeastern Spanish Mediterranean coast, will be evaluated as an example to illustrate the methodology. This environment is quite enlightening as it presents many of the problems that can develop in the Mediterranean area (mass tourism, intensive agriculture, urban sprawl, water needs, infrastructures, etc.). The four phases of the process described will be carried out, and the results of this analysis process will enable proposals for implementing actions towards the development of a sustainable and healthier territory to be raised.

The first step in the analysis process has been done through the SDIMED GIS tool identifying the main variables, issues, driving forces, pressures, stakeholders, etc. of land transformation at a)

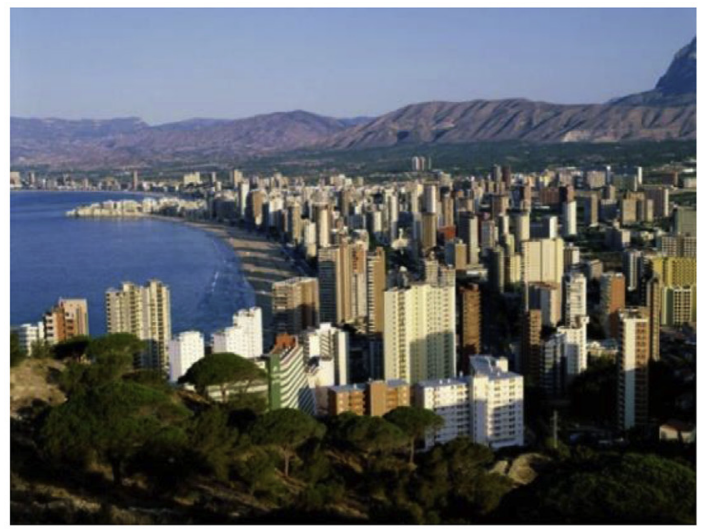

c)

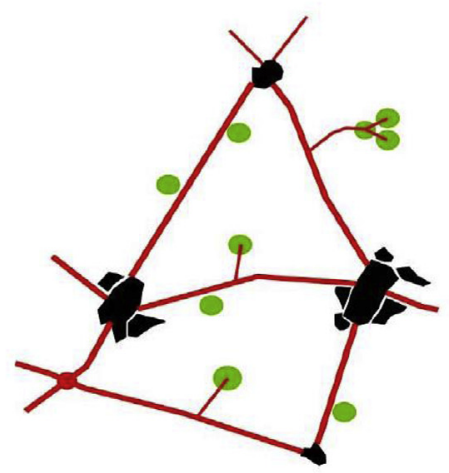

b)

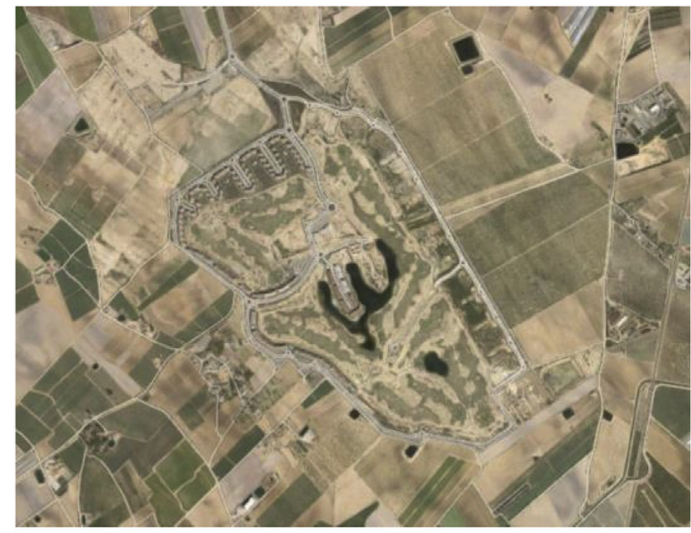

d)

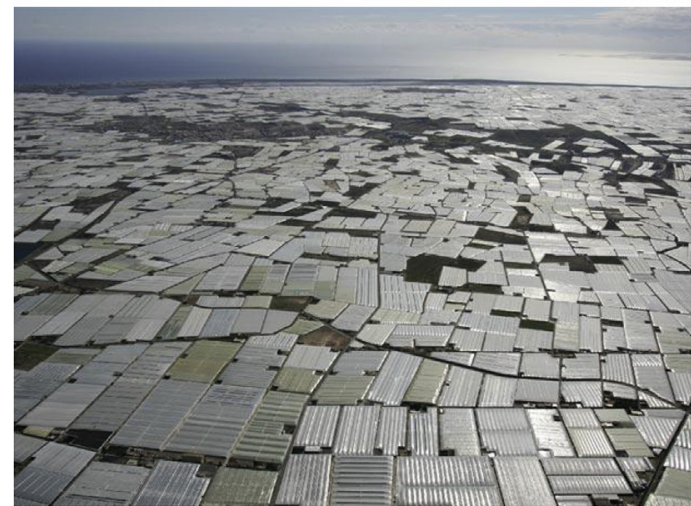

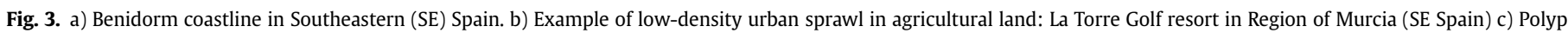

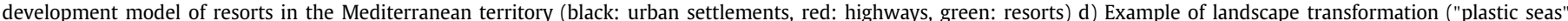

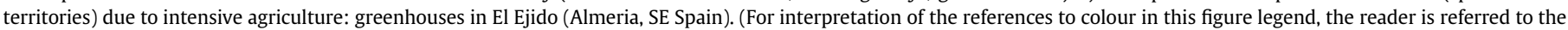
Web version of this article.) 
macro-structural level in a defined geographical area (see Fig. 4 and supplementary GIS data). This area is a coastal territory of high environmental value located in the Region of Murcia, with a stable population of 300,000 inhabitants that doubles in the summer months. The territory, with half a dozen well-defined mediumsized urban settlements, hosts a large and varied economic activity acting as driving forces: intensive agriculture, golf resorts, tourism of sun and beach, extinct mining, urban sprawl, etc. Many such activities are developed around the Mar Menor, a coastal lagoon of high ecological value separated from the Mediterranean Sea by an ancient sandy bar called La Manga, which is now highly urbanized. In this first stage, the first data of land transformation processes (accumulated land consumption (16\%), growth rates $(2.6 \%)$ or annual urban intensities (3.8\%)) can be observed as normal in comparison to other nearby territories. Other interesting figures can also be found on the consumption of resources (for example, current global water needs are $267 \mathrm{Hm}^{3}$ of which $75 \%$ is for crops, with urban use being $172 \mathrm{l} /$ person/day), the high rates of infrastructures (almost $400 \mathrm{~km}$ of highway and two airports in $600 \mathrm{~km}^{2}$ of territory) or the weights of the various economic activities in the area (agriculture 5.5\% of GDP vs. tourism 11\%). Therefore, initially the signs of an unbalanced development or distortion factors in contrast to its territorial environment would not be readily visible.

The real behaviour of these results must be implemented through the "retrohistorical" trend analysis to be developed in the second phase. This section must be performed as per the recommendations of the previous section so that the incorporated data are statistically significant in modelling robust trends (the following study has been done taking 60 years in three periods, from 1956 when mass tourism began, until now). In this case it has been implemented using historical georeferenced cartography, as can be observed in Fig. 5. Significant growth can be appreciated in this phase both for buildable land declared in the last 25 years ( $141 \%$, for an increased population estimated at $61 \%$ ) as well as the exponential growth rate of land transformation for intensive agriculture (446\%) since the Tagus-Segura river transfer began in 1981.

The next phase is to address the incorporation of the limitations that current regulations/planning impose and the boundary conditions generated by the existing physical reality at an orographic and social level. These limitations allow us to channel the trend hypothesis in a realistic framework which is adjusted to the possibilities of planned development. In this sense, in the analysis it is particularly interesting to observe the current urban planning framework for the area. It is especially relevant its evolution over the last 15 years for buildable land for resorts and the agricultural uses vs. natural areas (see Appendix A). Furthermore, a more detailed analysis is required in order to incorporate environmental issues affecting the Mar Menor lagoon caused by the arrival of nitrates through contributions from wadis as a result of the significant increase in intensive farming land in the area. In this context, apart from the above GIS scenario needed to implement the urban or environmental constraints, it is necessary to incorporate LiDAR

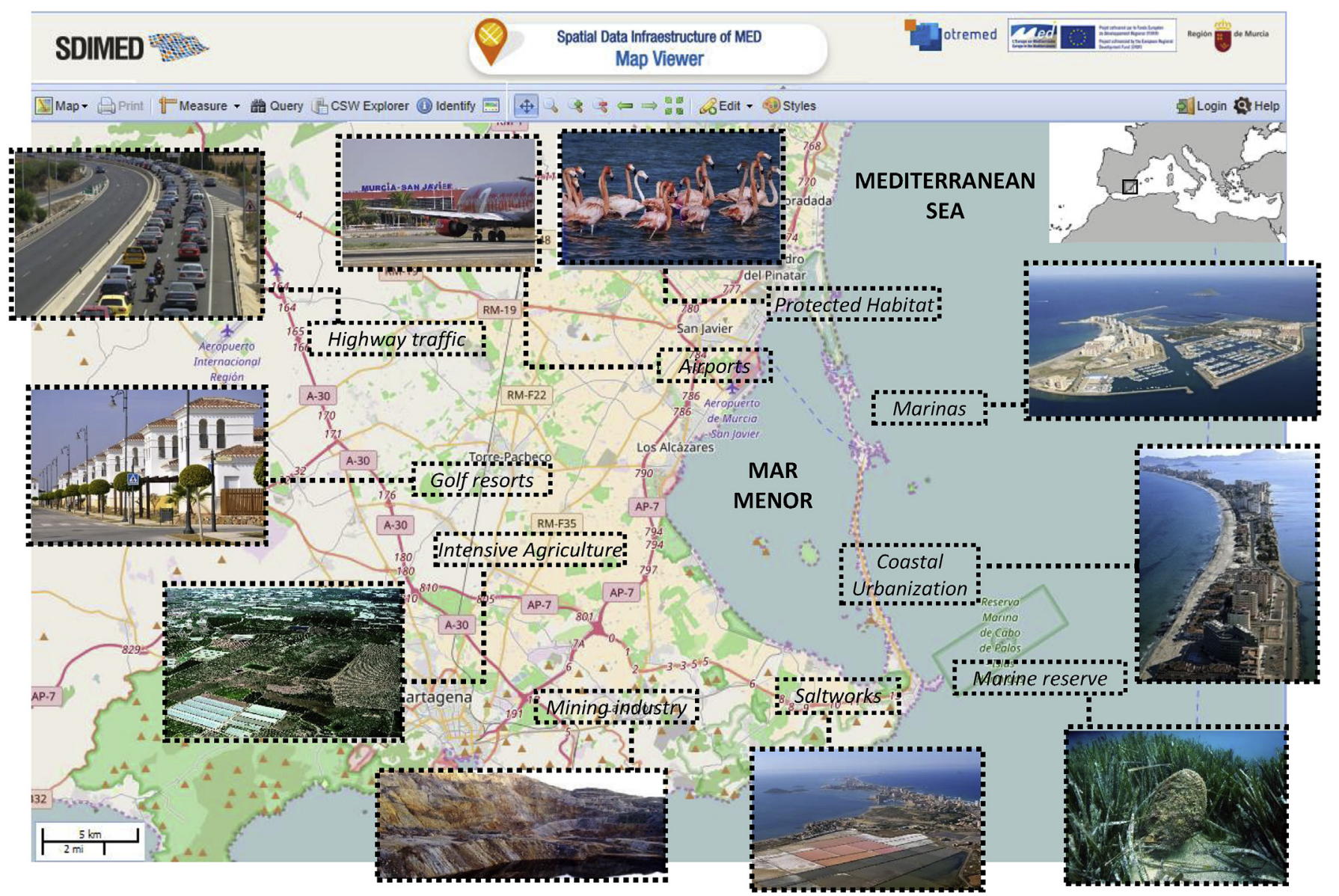

Fig. 4. Area selected for study and catalogue of existing anthropic activities. Source: SDIMED. 


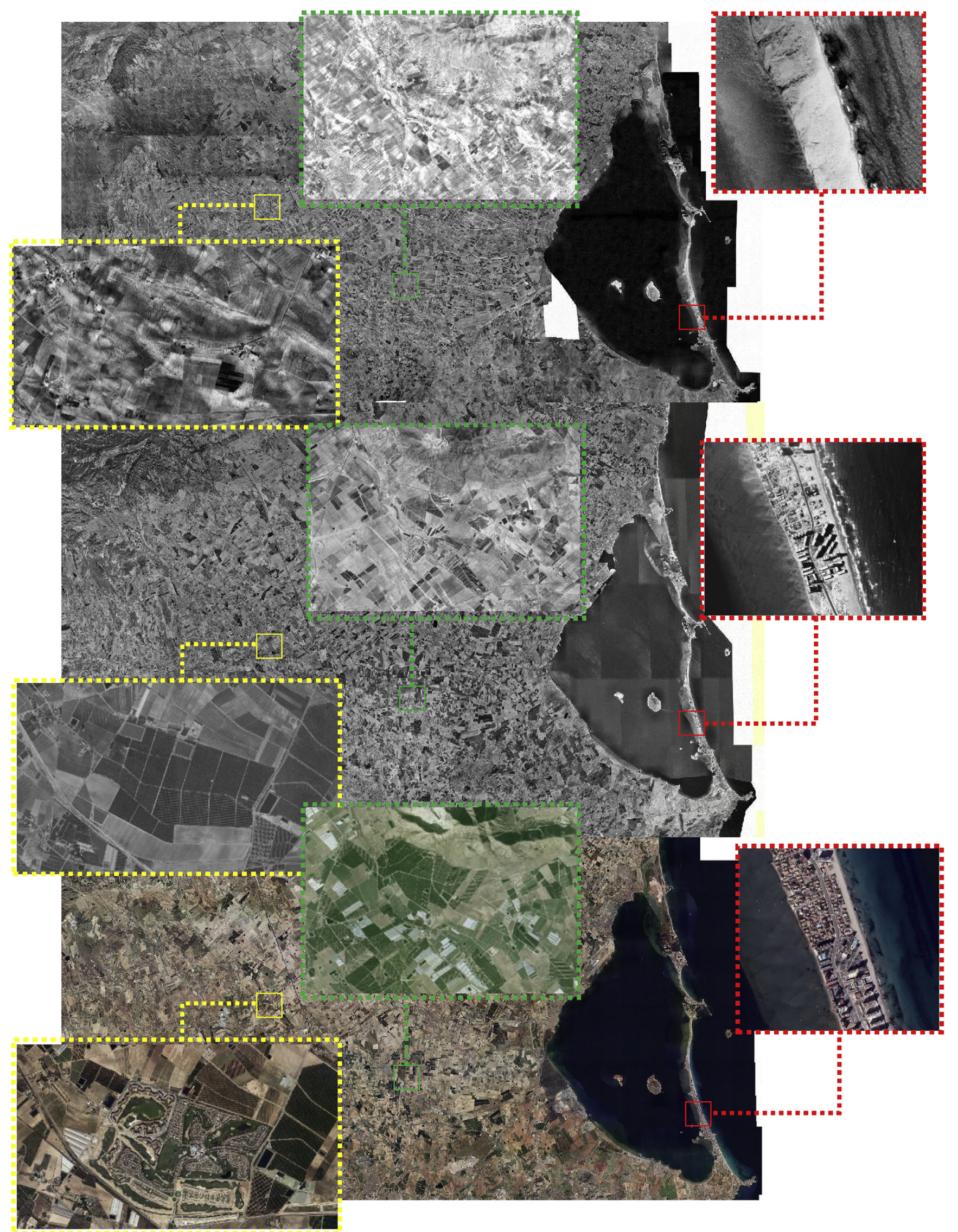

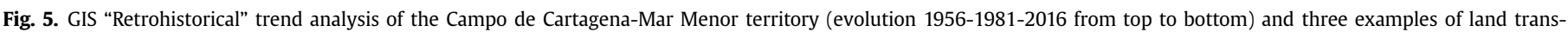

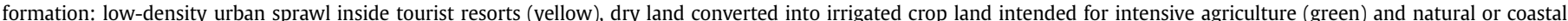

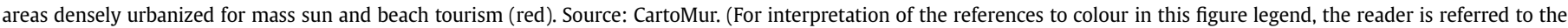
Web version of this article.) 
information to correctly model all the boundary conditions that simulate the physical reality of the territory. In this case study, the environmental constraints are particularly conditioning, with specific attention focused on the impacts of landscape transformations due to the orographic complexity of the area. For example, the transformation of traditional terraced crops or natural soil with dense shrub vegetation into greenhouse surfaces plowed in the direction of the terrain slope raise several controversies.

On the one hand, important issues are observed between the existing wadi connections to the lagoon and intensive agriculture. Moreover, land transformation of natural terrain linked to new typologies of crops must also be carefully studied for hazard risk analysis (Fig. 6, for example the usual torrential rains of autumn in the Mediterranean climate generated unusual historical catastrophic damage in the coastal town of Los Alcazares in December 2016). On the other hand, imbalances regarding the proliferation of small urban cores as tourist resorts around the A-30 and RM-19 highways (Appendix A) must also be evaluated carefully in the following stage as they may highlight a future source of problems related to resource consumption due to urban sprawl.

Finally, the fourth stage is configured by correcting the inertial approaches (2nd phase) of the variables of the first section, taking into account the boundary conditions of the third stage. The implementation of this forecasting stage helps us to establish which issues may arise in the future and introduce which decisions are needed to modify the current inertia in order to prevent such issues. Therefore, it should be noted that this operation will demand implementing heterogeneous numerical data from the previous three phases and translate it in a homogenous process into aggregated simple and understandable variables (the criteria applied for this case study can be found in Appendix B).

\section{Results}

For the area studied, after implementing the results of the four stages described, future scenarios for 2025 can be simulated (see Fig. 7 as an illustrative graphical sample of part of them and Table 1 as an aggregate summary of all the resulting measurements). In that context, we can appreciate for example how land urban consumption and global land transformation rates of $45 \%$ and $68 \%$ may be achieved for that date.

These results from the simulation reveal that current trends will generate a considerable boost in resource demand for urban sprawl resorts and environmental impacts linked to agricultural activity near the protected area of the Mar Menor lagoon. This scenario shows important imbalances from the point of view of water supply infrastructures, both because of the significant increase in their need to attend services derived from low density urban sprawl (94\%) and for the growth in global water needs due to the new surface area of intensive agriculture (future water deficit of $397 \mathrm{hm}^{3}$ representing an increase of $48.8 \%$ ). In this sense, an important oversizing in the transport infrastructure capacity rate is also appreciated (MDI of 86,000 supported for average values of 6000 to 33,000) which is conditioned by the important forecast linked to land consumption growth. Paradoxically, it will not be able to "digest" the usual traffic jams in summer caused by tourism seasonality (see Appendix B).

Another particularly interesting fact to observe is how urban sprawl in certain risk environments such as wadis (or areas affected by localized flash floods) may generate increasing hazard issues

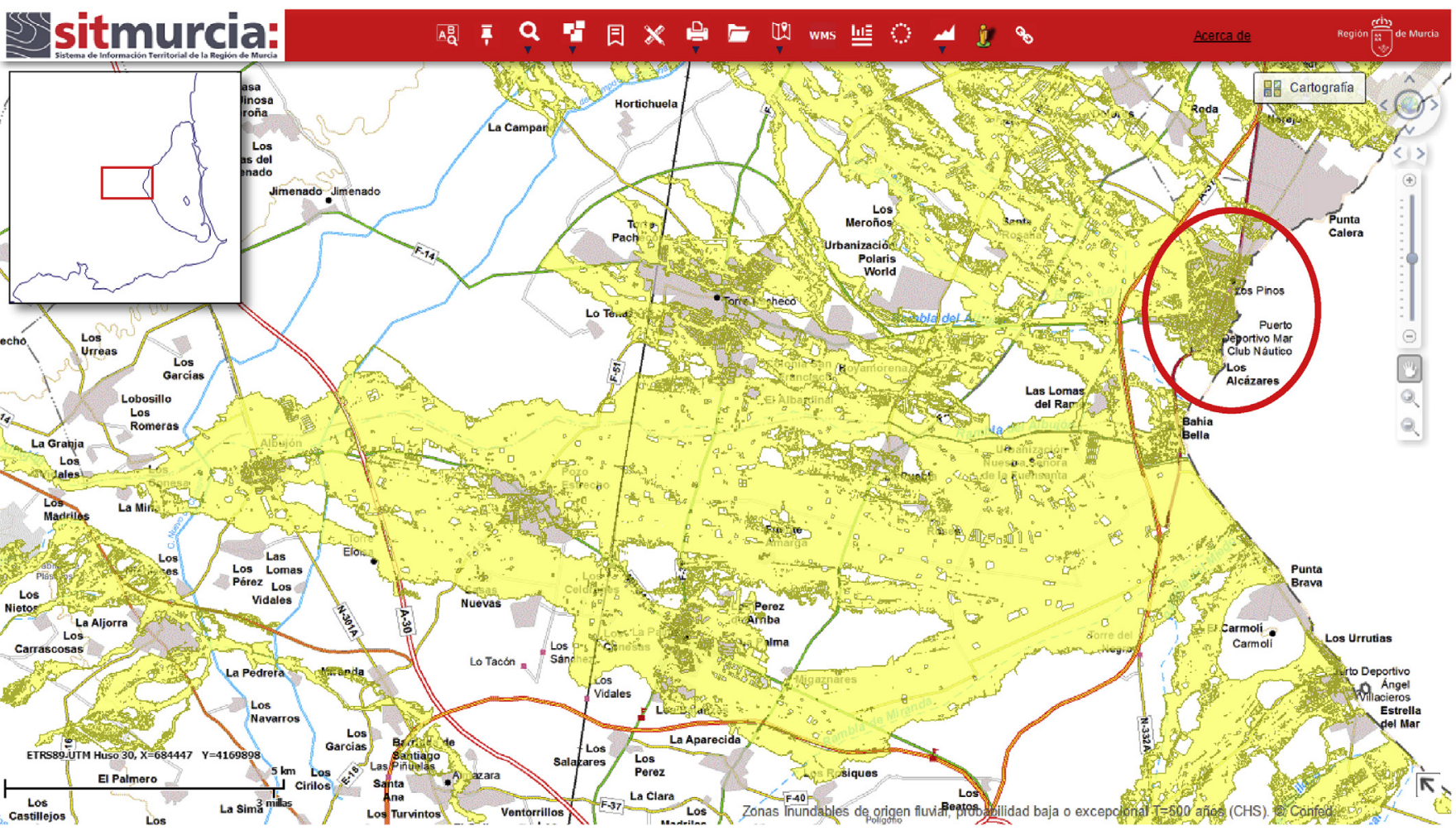

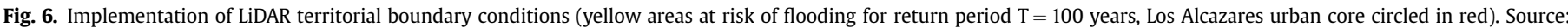
Sitmurcia (input data from LiDAR Murcia). (For interpretation of the references to colour in this figure legend, the reader is referred to the Web version of this article.) 
(risk area multiplied by four in 2025). It can also be clearly seen how urbanization resorts developed in a scattered way in the past create problems in their management today due to their low socioeconomic profitability. In that context, some basic services such as public transport are not available in these areas where it is unsustainable in its current configuration. Finally, the global landscape transformation is a particularly relevant aspect $(32,445 \mathrm{Ha}$ transformed in 25 years), providing a good summary of an unbalanced development model.

\section{Discussion}

The methodology presented represents, to a certain extent, an evolution on the classic methods of geodesign (Steinitz, 2000) and the current application of Big Data to the concept of smart city (Hashem et al., 2016). The extension of the framework to a broader territorial scope that includes several different urban settlements and the implementation of future scenarios based in retrohistoric analysis of land consumption raise as a new approach to the case study analysed. This can provide, for example, a more comprehensive assessment of issues and phenomena in the area, different from that of existing studies (Perez-Ruzafa et al., 2005; Velasco et al., 2006; Garcia-Ayllon, 2015; etc.) which have often been more oriented to a unidisciplinary analysis. In this sense, the results obtained in relation to the trend scenarios present an interesting and new debate specially regarding the correlation between the three different elements whose evolution has been highlighted through land consumption analysis. These three elements are: the urban sprawl development model within the Campo de Cartagena area, the process of agricultural transformation in that territory derived from the Tagus-Segura river transfer, and high-density urbanization linked to seasonal mass tourism on the Mar Menor coast. Through the analysis carried out, these three elements have been observed to be responsible for most of the present and future issues diagnosed.

Chronologically we have observed that the first phenomenon to appear was that of high-density urbanization, linked to mass tourism looking for the sun and the beach. This process has saturated the coastal perimeter of the Mar Menor and its surroundings since the 1960 s, causing important natural assets of the area such as the old dune strip called La Manga to disappear. This phenomenon could have occurred due to the lack of environmental legislation until the 1980s (Garcia-Ayllon, 2015), and is currently stabilized due to the tightening of environmental standards and the significant saturation of the area which tends to guide the real estate market to other places. The process has generated a compact urban area with a moderate consumption of resources (water, energy, transport infrastructure, etc.) per person, but has consolidated a model of second homes based on extreme seasonality. This phenomenon has proved to be extremely inefficient from the point of view of city design for urban management since it requires a significant investment in

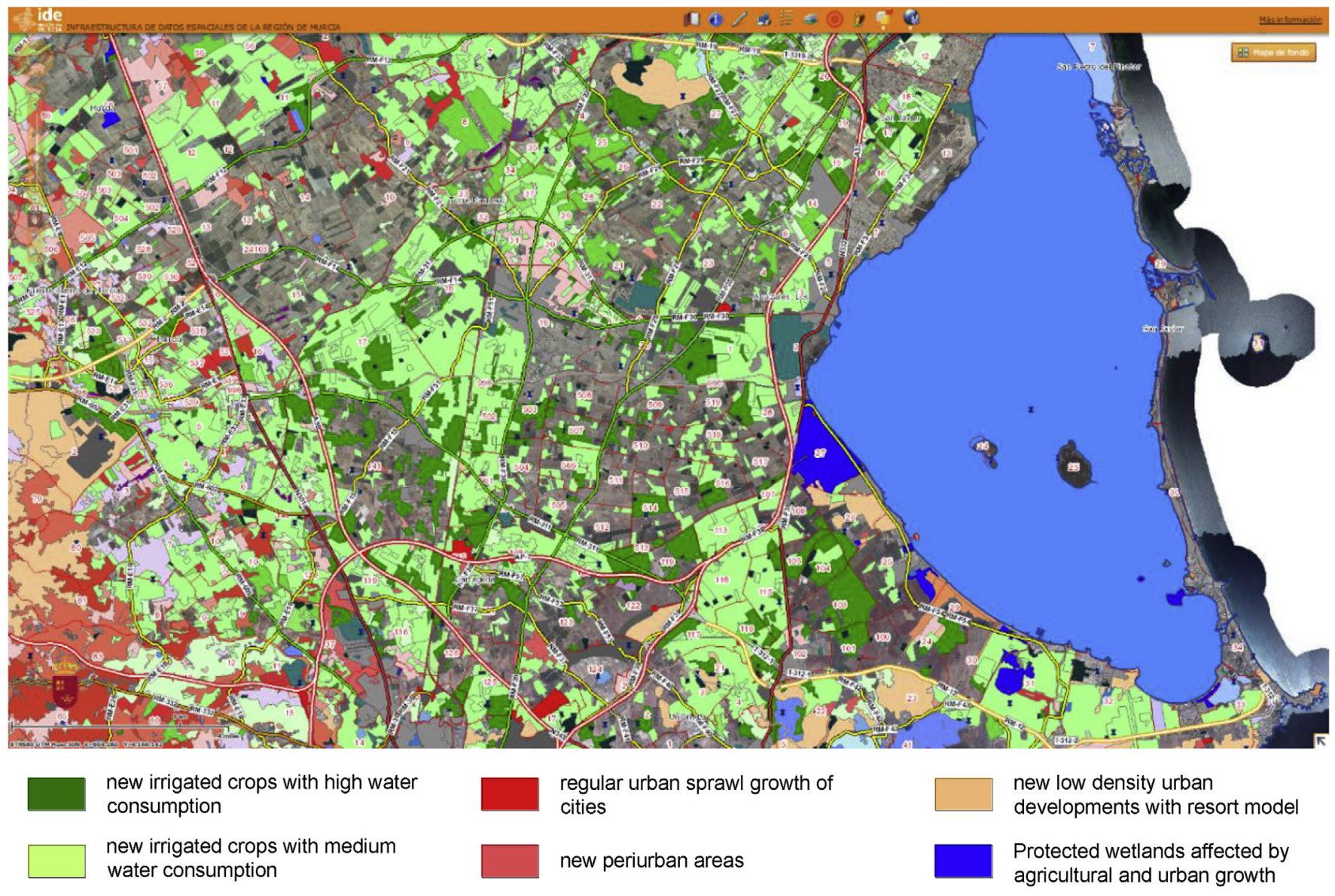

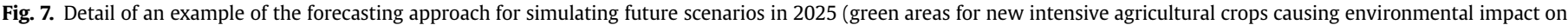

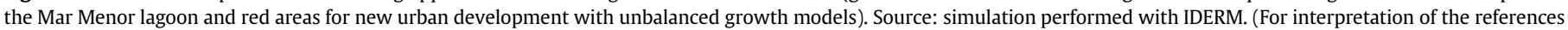
to colour in this figure legend, the reader is referred to the Web version of this article.) 
infrastructure (roads, electricity distribution, water treatment, services, etc.) to meet the needs of a population during only one or two months per year. This causes inefficiency for oversizing and additional problems (regular traffic jams, power outages in summer, etc.) that prevent the development of high quality tourism, quite the opposite to a smart territory design.

On the other hand, from the early 1980s the water transfer between the Tagus and Segura rivers started, which transformed the agriculture of the territory, converting it into one of the most productive agricultural territories of Europe. This new area, currently called "the orchard of Europe", has brought considerable wealth to the surrounding populations. This has however come at the cost of generating important disadvantages such as the environmental impact by the contribution of nitrates to protected natural areas like the Mar Menor (García-Sánchez et al., 2012) or the excessive dependence in the economy on the transfer of water from other territories, which is creating currently political controversies between regions (Pérez-Blanco and Gutiérrez-Martín, 2017; Gorostiza et al., 2017).

Finally, we have the case of the resort phenomenon, which is more recent and acts as a link between the two previous ones. This phenomenon began in the mid-1990s encouraged by the authorities as a tourist alternative to the former coastal urbanization (Martí et al., 2017), whose growth was in the process of exhaustion in real estate due to the reasons stated above. The resorts took advantage of the important existing transport infrastructures

Table 1

Summary of 1956, 1981 and 2016 parameters analysed and forecast of future scenario for 2025.

\begin{tabular}{|c|c|c|c|c|c|c|c|}
\hline & & & 1956 & 1981 & 2016 & Trend Scenario 2025 & Observations \\
\hline $\begin{array}{l}\text { Land consumption } \\
\quad(\mathrm{Ha})\end{array}$ & \multicolumn{2}{|c|}{$\begin{array}{l}\text { Low-density (L-D) tourism resorts (number/Ha) } \\
\text { Intensive agriculture }(\mathrm{Ha}) \\
\text { Coastal urbanization }(\mathrm{Ha})\end{array}$} & $\begin{array}{l}0 / 0 \\
4478 \\
728\end{array}$ & $\begin{array}{l}1 / 202 \\
14,762 \\
3362\end{array}$ & $\begin{array}{l}16 / 5714 \\
42,664 \\
4206\end{array}$ & $\begin{array}{l}27(10,816 ; \text { planned }) \\
56,776 \\
4487\end{array}$ & $\begin{array}{l}\text { - Progressive increase } \\
\text { of land consumption } \\
\text { for low-density } \\
\text { tourism resorts and } \\
\text { intensive agriculture } \\
\text { (94\% and } 45 \%) \\
\text { - Progressive } \\
\text { stabilization of land } \\
\text { consumed in the } \\
\text { coast }\end{array}$ \\
\hline $\begin{array}{l}\text { Total land } \\
\text { transformed rate } \\
(\%)\end{array}$ & $\begin{array}{l}\text { Whole Campo de Cartagena area } \\
\text { 1st-km coastal edge }\end{array}$ & $\begin{array}{l}\text { Urban sprawl } \\
\text { Irrigated crops }\end{array}$ & $\begin{array}{l}3.1 \\
3.6 \\
9.3\end{array}$ & $\begin{array}{l}10.7 \\
22.4 \\
56.6\end{array}$ & $\begin{array}{l}18.1 \\
25.6 \\
69.2\end{array}$ & $\begin{array}{l}24.4 \\
43.6 \\
71.1\end{array}$ & $\begin{array}{l}\text { - Urban sprawl } \\
\text { reduced between } \\
2008 \text { and } 2013 \text { due to } \\
\text { economic crisis } \\
(-33.6 \%) \\
\text { - Clogging symptoms } \\
\text { by } 2025 \text { of artificially } \\
\text { transformed land } \\
\text { (68\%): landscape } \\
\text { alteration and } \\
\text { affection to natural } \\
\text { areas }\end{array}$ \\
\hline \multicolumn{3}{|c|}{ Road Infrastructure $(\mathrm{km}$, normal road $\times 1$; highway $\times 2$ ) } & 115 & 277 & 880 & 895 (planned) & \multirow{3}{*}{$\begin{array}{l}\text { - Global over- } \\
\text { dimensioning of road } \\
\text { infrastructures } \\
\text { (average MDI sup- } \\
\text { ported of 86,000) } \\
\text { - Nonetheless } \\
\text { significant regular } \\
\text { traffic jams in specific } \\
\text { areas of A-30 and } \\
\text { RM-19 highways } \\
\text { during the summer } \\
\text { months due to } \\
\text { seasonality. } \\
\text { - Progressive growth in } \\
\text { the structural water } \\
\text { deficit of the area } \\
\text { (48.8\%) in line with } \\
\text { the progressive land } \\
\text { transformation. }\end{array}$} \\
\hline $\begin{array}{l}\text { Average/Peak } \\
\text { Traffic (Medium } \\
\text { Diary Intensity of } \\
\text { vehicles, MDI) }\end{array}$ & $\begin{array}{l}\text { RM-19 highway } \\
\text { A-30 highway (La Manga part) } \\
\text { Secondary roads }\end{array}$ & & $\begin{array}{l}\text { No data } \\
\text { No data } \\
\text { No data }\end{array}$ & $\begin{array}{l}8742 / 25,617 \\
4544 / 31,768 \\
897 / 1103\end{array}$ & $\begin{array}{l}19,099 / 66,707 \\
5646 / 77,682 \\
1287 / 1761\end{array}$ & $\begin{array}{l}33,537 / 88,922 \\
6104 / 81,330 \\
2108 / 2875\end{array}$ & \\
\hline Global agricultural w & Jater deficit for the Campo de Cartag & ena area $\left(\mathrm{Hm}^{3}\right)$ & 25 & 122.6 & 267.3 & 397.8 & \\
\hline \multirow{4}{*}{$\begin{array}{l}\text { Waste of energy } \\
\text { and water supply } \\
\text { (Kwh } 10^{6} / \text { year) }\end{array}$} & Main housing & & 114.3 & 135.1 & 166.8 & 169.2 & \multirow{4}{*}{$\begin{array}{l}\text { - Energy and water } \\
\text { supply cost per } \\
\text { person much higher } \\
(\times 2.7) \text { in low-density } \\
\text { urban sprawl resorts } \\
\text { vs. current main } \\
\text { housing }\end{array}$} \\
\hline & Coastal 2nd homes & & 0.3 & 18.7 & 44.6 & 45.8 & \\
\hline & Hotels & & 1.1 & 11.7 & 14.4 & 14.5 & \\
\hline & L-D Tourism resorts & & 0 & 0.3 & 27.5 & 35.7 & \\
\hline \multicolumn{3}{|c|}{ Urban cores subject to flooding risk (Ha, $\mathrm{T}=100$ years) } & None found & 5.2 & 88.7 & 356.5 & $\begin{array}{l}\text { - Landscape } \\
\text { transformation by } \\
\text { intensive agriculture } \\
\text { increases risk of } \\
\text { flooding in some } \\
\text { resorts and coastal } \\
\text { areas of Mar Menor }\end{array}$ \\
\hline
\end{tabular}


(highways) and consumed agricultural or natural land far from the coast (therefore much cheaper) to develop a model based on lowdensity urban sprawl. This type of urban development theoretically proposes a more sustainable urban sprawl model since it does not require new infrastructures and reduces seasonality from the coastal model (a more residential tourism geared towards golf and good weather with a population that remains all year, Ahn and Back, 2018). Nevertheless, as has been verified in the results, this excessively low-density development leads in that context to a very inefficient dispersed model of high consumption of soil and resources. The results show an extremely high impact cost per person, in which many basic services (public transport, social facilities, etc.) are not even guaranteed for their inhabitants, as can been observed in other Mediterranean areas (Morote and Hernández, 2016).

This last phenomenon has cohabited in its growth physically during the last two decades with the phenomenon of agricultural transformation. Several parcels that were initially transformed for irrigated crops were later transformed into plots for resorts, many of which were stopped from 2008 due to the real estate crisis and have now been resumed as a result of the economic recovery and investments by foreign funds. In this sense, several questions are raised: Is this resort model a solution to reduce seasonality problems of coastal urbanization? Can the current agricultural growth cohabit adequately with urban resort growth and the Mar Menor environmental issues? Are these land transformation rates sustainable for the future?

In the light of the results obtained, the answer must be no. Both urban sprawl models, without being intrinsically bad, were developed in an incorrect way since, as shown, they lead to unbalanced results. In this sense, taking into account that most of the urban planning processes currently planned or authorized cannot be legally reversed, then a rebalancing program should be implemented first. This program must be able to unseasonabilize the tourism supply and to enhance different urban growth models. The new models must not encourage cost reduction alternatives to private developers (for example land costs) that generate urban configurations causing future unbalanced consumption of public resources per person (water or energy infrastructure) or unaffordable provision of services (public transport). Moreover, land transformation growth associated to agriculture must be better controlled in order not to continue to deepen the imbalances of water requirements.

On the other hand, the cohabitation is complicated but necessary since all the three phenomena are interrelated, as has been shown. In the case of agriculture and coastal tourism we might even be facing a problem of cost transfer between different sectors. The current profitability of the agriculture sector of the area is linked to the "industrialization" of traditional crops. Nevertheless, its use of fertilizers and phytosanitary products damages the coastal lagoon and consequently the tourism sector (in 2015 the Mar Menor waters turned green because of turbidity caused by nitrates from agriculture, generating social alarm and important losses to tourism, Garcia-Ayllon, 2017). In this sense, some solutions related to the Mar Menor environmental issues should be financed by private stakeholders from agriculture in the future rather than by public administrations, as is usually the case.

Lastly, it is important to correctly channel the current inertia trends of land transformation associated to resort tourism and agriculture. Land is a scarce resource in territories of high economic activity and an indirect indicator of further issues in other resources, as has been observed. In this sense, it would be interesting to reach a consensus with public and private stakeholders for implementing planning programs introducing the term "global capacity limit" of the territory beyond the usual administrative divisions. This concept applied through the proposed methodology could help authorities and decision makers in development and territorial management (in the case of Spain, primarily local and regional administrations) to diagnose, stop and even reverse situations that lead to unsustainable scenarios. This could prove to be an adequate solution in contexts such as the one analysed where the diverse interests of the different cities from the Campo de Cartagena area are not able to assess the complexity of the progressive imbalance of the global territory.

\section{Conclusions}

The path from the concept of smart city to that of smart territory is revealed in some cases as a necessary leap ahead to address the management of our environment in a comprehensive manner. This paper has presented a four-step methodology called retrospective GIS-LiDAR analysis in order to diagnose scenarios that in the future may pose various problems or potential risks based on the inertia detected in the present. This process based in retrohistorical analysis of land consumption allows policy makers to anticipate future problems and correct them through proper territorial planning in the present. The methodology has been applied in the Mar Menor-Campo de Cartagena Mediterranean area through spatial tools that shown an unsustainable future scenario in 2025. Nevertheless, it can be used on any other area of the world to reconduct territorial models that generate unaffordable development trends.

The results obtained, and the methodology in itself, can be very useful to understand, at a territorial scale, complex interrelated issues that occur in areas of high economic activity of developed countries (water or energy consumption on gated communities, infrastructure oversizing, etc.) or to correct unbalanced growth models in developing countries (diffuse environmental impacts, indirect generation of hazard risks associated to uncontrolled urban growth, etc.). The approach performed obviously has certain limitations since, as has been presented, it requires sufficient georeferenced historical information. In addition, it is necessary to make a preliminary analysis in the first phase able to translate existing multivariable problems into homogeneous data based on land consumption indices (which can make the analysis more complex in other territorial contexts). Even so, the approach is clearly innovative because it represents an evolution of the classic geodesign methodologies and is proposed as an open-phased methodology capable of adapting to different contexts simply by modifying spatial analysis tools.

\section{Appendix C. Supplementary data}

Supplementary data related to this article can be found at https://doi.org/10.1016/j.jclepro.2018.02.160.

\section{Appendix A. Urban planning boundary conditions}



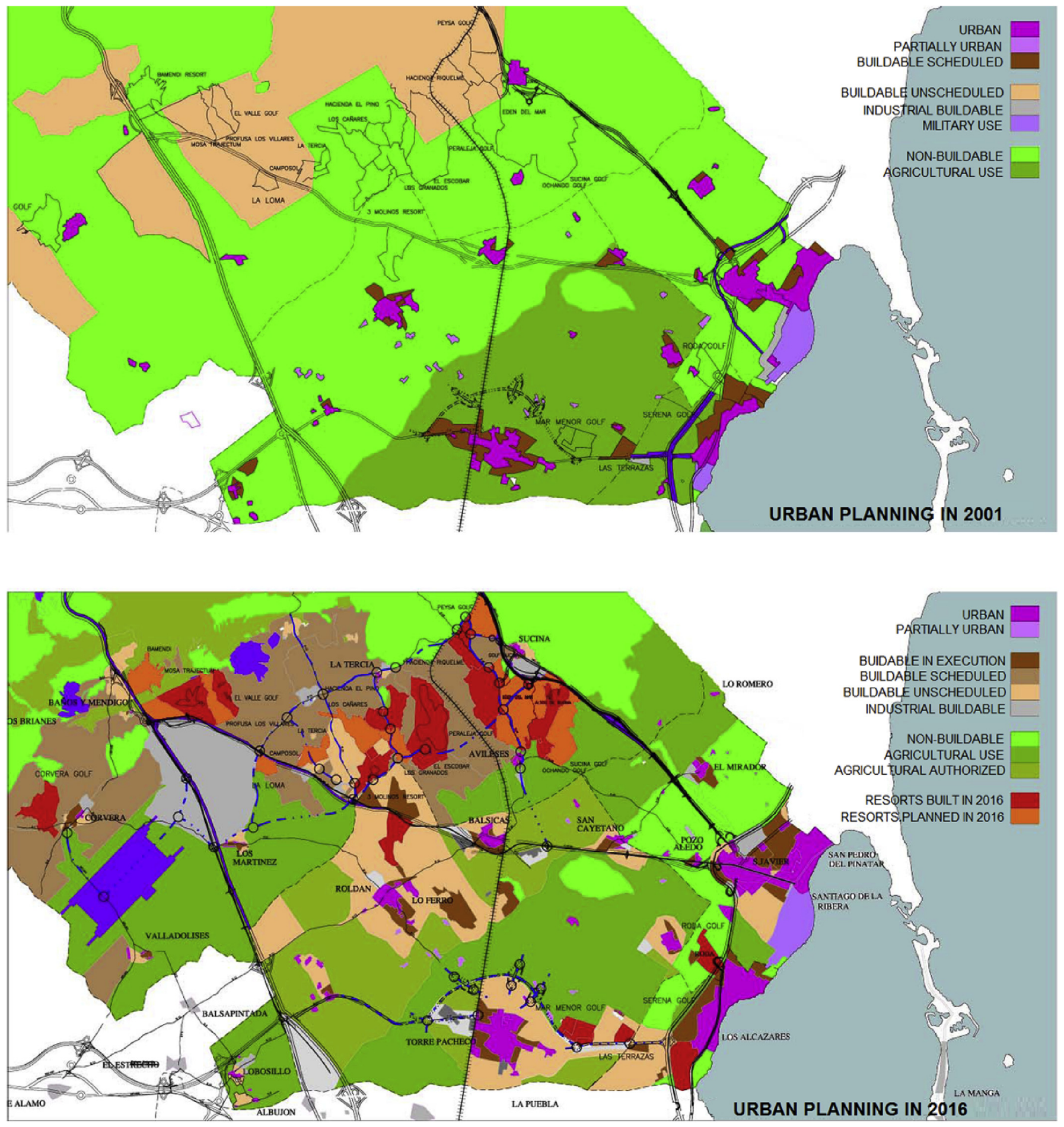

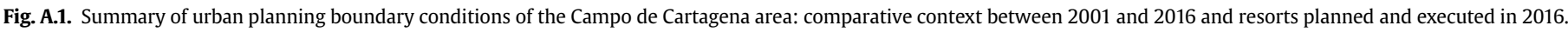
Source: SDIMED. 


\section{Appendix B. forecasting criteria applied.}

Table.B.1

Criteria of land analysis and parameters used.

\begin{tabular}{|c|c|c|c|c|c|}
\hline & & 1956 & 1981 & 2016 & 2025 \\
\hline Analysed Area & \multicolumn{5}{|c|}{$\sum$ SPArea $=649.2 \mathrm{~km}^{2}$ (see GIS supplementary digital material provided) } \\
\hline \multicolumn{2}{|c|}{ Street-towns model } & 49 & 374 & 817 & $\begin{array}{l}1004 \text { (linear } \\
\text { estimation trend) }\end{array}$ \\
\hline \multirow[t]{2}{*}{ Parcels analysed } & Urban & 1264 & 3785 & 5560 & 6169 (fig. A1 trend) \\
\hline & Agricultural & 894 & 1670 & 1232 & $\begin{array}{l}1334 \text { (linear } \\
\text { estimation trend) }\end{array}$ \\
\hline \multicolumn{2}{|l|}{ Pop $=\sum$ parcelpop } & 81,700 & 372,200 & 562,800 & $\begin{array}{l}721,500 \\
\text { (estimation trend) }\end{array}$ \\
\hline \multicolumn{2}{|c|}{ LCI (HU), LCI (TU), LCI (AC) } & \multicolumn{4}{|c|}{$\begin{array}{l}\text { Results homogenously parameterized in Table } 1 \text { of manuscript } \\
\text { in Ha and \%. }\end{array}$} \\
\hline $\mathrm{LCI}(\mathrm{RI})$ & \multicolumn{5}{|c|}{$\begin{array}{l}\text { GIS road infrastructure measured lineally in } \mathrm{km} \text { (correction coefficient } \times 1 \text { for normal and secondary roads and } \times 2 \text { for highways, data analysed } \\
\text { and average intensity levels in Fig. B1) }\end{array}$} \\
\hline Traffic levels & \multicolumn{5}{|c|}{$\begin{array}{l}\text { Data from appraisals conducted on motorways. Future estimations based on projections of population and growth of tourist settlements. } \\
\text { Secondary roads expressed as average of them. }\end{array}$} \\
\hline Global Water needs & \multicolumn{5}{|c|}{$\begin{array}{l}\text { Water deficit data obtained on the basis of hydrological basin plans of the Ministry of Agriculture of Spain for each historical milestone taking } \\
\text { into account the area cultivated in each case. Forecasting to } 2025 \text { obtained on the basis of crop growth according to irrigation typologies } \\
\text { following Corine Land Cover criteria (Corine Land Cover, 2006). }\end{array}$} \\
\hline \multirow{4}{*}{$\begin{array}{l}\text { Average cost of } \\
\text { energy and } \\
\text { water supply } \\
\text { consumption }\end{array}$} & Main housing & 1 & \multirow{4}{*}{\multicolumn{3}{|c|}{$\begin{array}{l}\text { Waste energy based on population and cost per person } \\
\text { analysed for different urban models evaluating the summation } \\
\text { of resource supplied cost including energy transport plus the } \\
\text { impact of supply infrastructure cost }\end{array}$}} \\
\hline & Coastal 2nd homes & 1.05 & & & \\
\hline & Hotels & 0.9 & & & \\
\hline & Low-Density Tourism resorts & 2.7 & & & \\
\hline
\end{tabular}

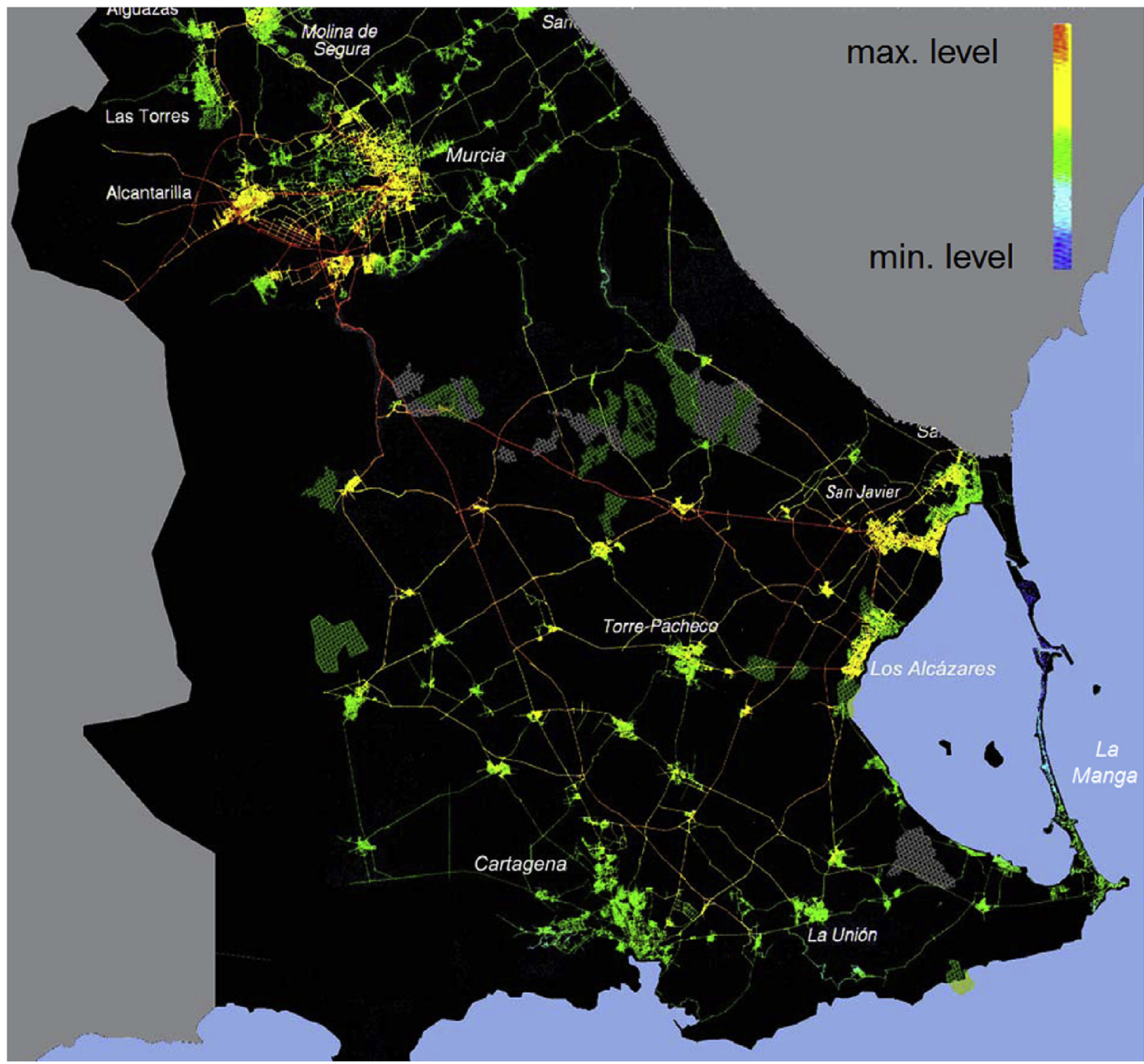

Fig. B.1. Road infrastructure model and traffic intensity analysis in the area (average annual intensity)

Please cite this article in press as: García-Ayllón, S., Retro-diagnosis methodology for land consumption analysis towards sustainable future scenarios: Application to a mediterranean coastal area, Journal of Cleaner Production (2018), https://doi.org/10.1016/j.jclepro.2018.02.160 


\section{References}

Ahn, J., Back, K., 2018. Integrated resort: a review of research and directions for future study. Int. J. Hospit. Manag. 69, 2018.

Allais, R., Reyes, T., Roucoules, L., 2015. Inclusion of territorial resources in the product development process. J. Clean. Prod. 94, 187-197.

Amato, F., Pontrandolfi, P., Murgante, B., 2015. Supporting planning activities with the assessment and the prediction of urban sprawl using spatio-temporal analysis. Ecol. Inf. 30, 365-378.

Anthopoulos, L., 2017. Smart utopia vs. smart reality: learning by experience from 10 smart city cases. Cities 63, 128-148.

Ben Letaifa, S., 2016. How to strategize smart cities: revealing the SMART model. J. Bus. Res. 68, 1414-1419.

Callaway, L., 2016. Smart cities: the future of sustainable living. Renew. Energy Focus 17, 106-108.

Carter, D., 2013. Urban regeneration, digital development strategies and the knowledge economy: manchester case study. J. Knowledge Econ. 4, 169-189.

Cole, S., 2009. A logistic tourism model: resort cycles, globalization, and chaos. Ann. Tourism Res. 36, 689-714.

Corine Land Cover, 2006. European Environmental Agency report. CLC2006 Technical Guidelines, vol. 17.

De Jong, M., Joss, S., Schraven, D., Zhan, C., Weijnen, M., 2015. Sustainable-smart-resilient-low carbon-eco-knowledge cities; making sense of a multitude of concepts promoting sustainable urbanization. J. Clean. Prod. 109, $25-38$.

De Jong, M., Yu, C.H., Joss, S., Wennersten, R., Yu, L., Zhang, X., Ma, X., 2016. Eco city development in China: addressing the policy implementation challenge. J. Clean. Prod. 134, 31-41.

Deakin, M., Al Waer, H., 2011. From intelligent to smart cities. J. Intell. Build. Int. 3. $140-152$.

Fraker, H., 2013. The Hidden Potential of Sustainable Neighborhoods: Lessons for Low-carbon Communities. Island Press, Washington.

Garcia-Ayllon, S., 2015. La Manga case study: consequences from short-term urban planning in a tourism mass destiny of the Spanish Mediterranean coast. Cities 43, $141-151$.

Garcia-Ayllon, S., 2016. Geographic information system (GIS) analysis of impacts in the tourism area life Cycle (TALC) of a mediterranean resort. Int. J. Tourism Res. 18, 186-196.

Garcia-Ayllon, S., 2017. Diagnosis of complex coastal ecological systems: environmental GIS analysis of a highly stressed Mediterranean lagoon through spatiotemporal indicators. Ecol. Indicat. 83, 451-462.

García-Sánchez, M., Pérez-Ruzafa, I.M., Marcos, C., Pérez-Ruzafa, A., 2012. Suitability of benthic macrophyte indices (EEI, E-MaQI and BENTHOS) for detecting anthropogenic pressures in a Mediterranean coastal lagoon (Mar Menor, Spain). Ecol. Indicat. 19, 48-60.

Gorostiza, S., March, H., Sauri, D., 2017. Flows from beyond the pyrenees. The rhône river and Catalonia's search for water independence. Polit. Geogr. 60, 132-142.

Grossi, G., Pianezzi, D., 2017. Smart cities: utopia or neoliberal ideology? Cities 69, $79-85$.

Hader, H., Rodzi, 2009. The smart city infrastructure development and monitoring. Theor. Empir. Res. Urban Manag. 4, 1187-1195.

Hashem, I., Chang, V., Anuar, N., Adewole, K., Yaqoob, I., Gani, A., Ahmed, E., Chiroma, H., 2016. The role of big data in smart city. Int. J. Inf. Manag. 36, $748-758$.

Hollands, R., 2008. Will the real smart city please stand up?: Intelligent, progressive or entrepreneurial? City 12, 303-320.

Ji, W., Ma, J., Twibell, R.W., Underhill, K., 2006. Characterizing urban sprawl using multi-stage remote sensing images and landscape metrics. Comput. Environ. Urban Syst. 30, 861-879.

Kummitha, R.K.R., Crutzen, N., 2017. How do we understand smart cities? An evolutionary perspective. Cities $67,43-52$.

La Greca, P., Barbarossa, L., Ignaccolo, M., Inturri, G., Martinico, F., 2011. The density dilemma. A proposal for introducing smart growth principles in a sprawling settlement within Catania Metropolitan Area. Cities 28, 527-535.
Lee, J.H., Phaal, R., Lee, S.H., 2013. An integrated service-device-technology roadmap for smart city development. Technol. Forecast. Soc. Change 80, 286-306.

Mahizhnan, A., 1999. Smart cities: the Singapore case. Cities 16, 13-18.

Martí, P., Nolasco-Cirugeda, A., Serrano-Estrada, L., 2017. Assessment tools for urban sustainability policies in Spanish Mediterranean tourist areas. Land Use Pol. 67, 625-639.

Martínez-Alvarez, V., González-Ortega, M.J., Martin-Gorriz, B., Soto-García, M., Maestre-Valero, J.F., 2017. The use of desalinated seawater for crop irrigation in the Segura River Basin (south-eastern Spain). Desalination 422, 153-164.

McCormick, K., Anderberg, S., Coenen, L., Neij, L., 2013. Advancing sustainable urban transformation. J. Clean. Prod. 50,1-11.

Mena, J., 2010. The Urbanizing Model "Resort": Analysis, Context and Implications in the Field of Murcia and Mar Menor. PhD thesis. Technical University of Cartagena.

Morote, A.F., Hernández, M., 2016. Urban sprawl and its effects on water demand: a case study of Alicante, Spain. Land Use Pol. 50, 352-362.

Nam, T., Pardo, T., 2011. Conceptualizing smart city with dimensions of technology, people, and institutions. In: Proceedings of the 12th Annual Internationa Digital Government Research Conference on Digital Government Innovation in Challenging Times. ACM, New-York.

Neirotti, P., 2014. Current trends in Smart City initiatives: some stylised facts. Cities 38, 25-36.

Nicodemo, C., Raya, J.M., 2012. Change in the distribution of house prices across Spanish cities. Reg. Sci. Urban Econ. 42, 739-748.

O'Connell, L., 2009. The impact of local supporters on smart growth policy adoption. J. Am. Plann. Assoc. 75, 281-291.

Odendaal, N., 2003. Information and communication technology and local governance: understanding the difference between cities in developed and emerging economies. Comp. Environ. Urban Sys. 27, 585-607.

Palmer, A., Mathel, V., 2010. Causes and consequences of underutilised capacity in a tourist resort development. Tourism Manag. 31, 925-935.

Pérez-Blanco, C.D., Gutiérrez-Martín, C., 2017. Buy me a river: use of multi-attribute non-linear utility functions to address overcompensation in agricultural water buyback. Agric. Water Manag. 190, 6-20.

Perez-Ruzafa, A., Fernández, A.I., Marcos, C., Gilabert, J., Quispe, J.I., GarcíaCharton, J.A., 2005. Spatial and temporal variations of hydrological conditions, nutrients and chlorophyll a in a Mediterranean coastal lagoon (Mar Menor, Spain). Hydrobiologia 550, 11-27.

Pozoukidou, G., Ntriankos, I., 2017. Measuring and assessing urban sprawl: a proposed indicator system for the city of Thessaloniki, Greece. Remote Sens. Appl. Soc. Environ. 8, 30-40.

Ren, Y., Yan, J., Wei, X., Wang, Y., Yang, Y., Hua, L., Xiong, Y., Niu, X., Song, X., 2012. J. Environ. Manag. 113, 447-455.

Steinitz, C., 2000. Environmental Planning for Communities. Technology Transfer and Support Division. Office of Research and Development, United States Environmental Protection Agency, Cincinnati, Ohio.

Thite, M., 2011. Smart cities: implications of urban planning for human resource development. Hum. Resour. Dev. Int. 14, 623-631.

Velasco, J., Lloret, J., Millan, A., Marin, A., Barahona, J., Abellan, P., SanchezFernandez, D., 2006. Nutrient and particulate inputs into the Mar Menor lagoon (SE Spain) from an intensive agricultural watershed. Water Air Soil Pollut. 176 37-56.

Walravens, N., 2015. Mobile city applications for Brussels citizens: smart City trends, challenges and a reality check. Telematics Inf. 32, 282-299.

Wey, W., Hsu, J., 2014. New Urbanism and Smart Growth: toward Achieving a Smart National Taipei University District, vol. 42. Habitat International, pp. 164-174.

Yue, W., Lucy, Y., Fan, P., 2013. Measuring urban sprawl and its drivers in large Chinese cities: the case of Hangzhou. Land Use Pol. 31, 358-370.

Zhang, X., Skitmore, M., De Jong, M., Huisingh, D., Gray, M., 2015. Regenerative sustainability for the built environment - from vision to reality: an introductory chapter. J. Clean. Prod. 109, 1-10.

Zygiaris, S., 2013. Smart city reference model: assisting planners to conceptualize the building of smart city innovation ecosystems. J. Knowl. Econ. 4, $217-231$. 